\title{
ANALISIS KUALITAS PELAYANAN UNTUK MENINGKATKAN KEPUASAN KONSUMEN: STUDI KASUS GOLD'S GYM BANDUNG
}

\author{
Merita Bernik \\ Fakultas Ekonomi dan Bisnis, Universitas Padjajaran \\ E-mail: merita.bernik@unpad.ac.id
}

\begin{abstract}
ABSTRAK
Kesehatan merupakan hal yang paling utama dan menjadi bebutuhan primer dari setiap manusia. Salah satu cara untuk menjaga agar kita tetap sehat adalah dengan rajin berolah raga. Terdapat berbagai macam oleh raga yang dapat dilakukan, dan juga terdapat banyak fasilitas yang disediakan untuk berolah raga. Salah satu fasilitas yang dapat dimanfaatkan adalah fitness center. Salah satu fitness center di Bandung memiliki jumlah konsumen dan member yang terus meningkat. Hal tersebut menunjukan adanya kepuasan konsumen, dimana dalah satu indikator untuk memenuhi kepuasan konsumen adalah adanya kualitas pelayanan yang baik. Metode yang dipergunakan dalam penelitian ini adalah metoda deskriptif dengan menggunakan data primer dan data sekunder, data yang telah diperoleh kemudian diolah, dianalisis dan dimasukan ke dalam diagram kartesius. Hasil yang diperoleh kualitas pelayanan yang diberikan masuk dalam kategori cukup baik dan banyak indicator yang masuk dalam kuadran B dimana kualiatas pelayanan dianggap penting sebagai faktor penunjang kepuasan konsumen.
\end{abstract}

Kata kunci: kualitas pelayanan, kepuasan konsumen, kesehatan, fitness center, diagram kartesius

\section{ABSTRACT}

Health is the most common thing and becomes the primary need of every human being. One way to keep us healthy is to diligently exercise. There are various kinds of sports that can be done, and there are also many facilities provided for sports. One of the facilities that can be utilized is the fitness center. One fitness center in Bandung has an increasing number of consumers and members. This shows the existence of consumer satisfaction, one of variable to meet customer satisfaction is the existence of good quality service. The method used in this study is a descriptive method using primary data and secondary data, the data that has been obtained is then processed, analyzed and entered into the Cartesian diagram. The results obtained from the quality of services provided are in a fairly good category and many indicators are included in the B quadrant where quality is considered important as a factor supporting consumer satisfaction.

Keywords: service quality, customer staisfaction, healthfitness center, cartesius diagram 


\section{Merita Bernik}

\section{PENDAHULUAN}

Manusia mempunyai banyak kebutuhan, baik kebutuhan yang bersifat primer, sekunder, maupun tersier. Kebutuhan primer adalah kebutuhan yang mutlak diperlukan oleh manusia. Pemenuhan kebutuhan ini bersifat pokok, karena jika tidak dipenuhi akan mengakibatkan terganggunya kehidupan manusia secara signifikan. Salah satu contoh dari kebutuhan primer adalah kebutuhan manusia akan kesehatan (Kusuma, 2017). Kesehatan yang merupakan kebutuhan primer tidak mungkin terpenuhi dengan baik tanpa ada aktivitas fisik atau olahraga salah satu wujud dari usaha pemenuhan kebutuhan kesehatan bagi manusia dengan menggiatkan aktivitas fisik adalah hadirnya pusat-pusat kebugaran atau fitness center. Perkembangan Fitness Center yang pesat, mampu menjadi salah satu solusi masalah kurangnya aktivitas fisik atau gerak yang dialami manusia. Telah banyak Fitness Center yang memberikan berbagai macam fasilitas untuk berolah raga. Salah satu tujuan dari adanya Fitness Center tersebut adalah memudahkan para konsumenya untuk melakukan olah raga dalam waktu yang lebih fleksibel. Fasilitas yang diberikan di dalam ruangan, bahkan ada yang berlokasi di dalam Mall. Maraknya Fitness Center tersebut menyebabkan persaingan yang semakin ketat. Memberikan potongan harga ataupun fasilitas tambahan lainnya, merupakan salah satu keuntungan menjadi member.

Hal utama yang harus diperhatikan oleh fitness center adalah kepuasan konsumen, agar perusahaan dapat bertahan, bersaing dan menguasai pangsa pasar Fitness Center yang semakin besar. Perusahaan harus mampu mengidentifikasi dan menganalisis kebutuhan konsumen, hal-hal apa saja yang dianggap penting oleh para konsumennya dan perusahaan juga harus berusaha untuk menghasilkan kinerja sebaik mungkin agar dapat memuaskan pelanggannya. Salah satu cara untuk dapat memenuhi keinginan dan harapan dari konsumen pada Fitness Center adalah dengan meningkatkan kualitas pelayanan yang diberikan.

Kualitas layanan merupakan bentuk penilaian konsumen terhadap tingkat layanan yang diterima (perceived service) dengan tingkat pelayanan yang di harapkan (expected service). Kualitas jasa pelayan adalah setiap tindakan atau kegiatan yang dapat ditawarkan oleh satu pihak kepada pihak lain, pada dasarnya tidak berwujud dan tidak mengakibatkan perpindahan kepemilikan apapun (Kotler \& Amstrong, 2017; Lupiyadi, 2014). Fitness Gold's Gym Braga Bandung mempunyai pelayanan yang dapat memuaskan para konsumen baru maupun member aktif, dikarenakan ketika seorang konsumen pertama kali datang mendapatkan senyuman dan ucapan selamat datang oleh wellness coach, dan akan menjelaskan apa saja fasilitas yang ada di Gold's Gym. Kepuasan yang didapat adalah ketika semua program yang ditawarkan mampu memenuhi kebutuhan konsumen. 
Salah satu contoh adalah penurunan berat badan dan badan yang terasa lebih bugar yang terbukti berjalan lancar.

Tabel 1.

Peningkatan jumlah member Golds GYM

\begin{tabular}{ccc}
\hline $\begin{array}{c}\text { Jumlah } \\
\text { Member 2016 }\end{array}$ & $\begin{array}{c}\text { Jumlah } \\
\text { Member 2017 }\end{array}$ & $\begin{array}{c}\text { Jumlah } \\
\text { Member 2018 }\end{array}$ \\
\hline 198 & 213 & 318 \\
\hline
\end{tabular}

Berdasarkan Tabel 1 terlihat bahwa member di Golds Gym mengalami peningkatan dari tahun 2017 sebesar 7,57\% dan pada tahun 2018 naik sebesar 49,29\%. Maka perlu dilakukannya penelitian apakah peningkatan dari jumlah member tersebut merupakan dampak dari kualitas pelayan dan bagaimana kualitas pelayanan yang diberikan sehingga dapat meningkatkan kepuasan konsumen.

\section{LANDASAN TEORI}

\section{Kualitas Pelayanan}

Kualitas pelayanan akan memberikan dampak terhadap kepuasan konsumen, dimana setiap konsumen menginginkan agar produk atau jasa yang dihasilkan produsen dapat memberikan kepuasan kepada konsumennya (Kotler \& Amstrong, 2017). Kualitas pelayanan diukur berdasarkan lima dimensi yang dikenal dengan nama TERRA yaitu (Tjiptono, 2018):

1) Keandalan (Reliability) yaitukemampuan memberikan pelayanan dengan segera;

2) Daya tanggap (Responsiveness) yaitu keingin para staf untuk memberikan pelayanan dengan tanggap dan membatu konsumen untuk memecahkan masalah;

3) Jaminan (Assurance) adalah mencakup pengetahuan, kompetensi, kesopanan dan dapat dipercaya dari karyawan;

4) Perhatian (Empathy) yaitu sikap karyawan yang memberikan perhatian yang tulus kepada konsumennya;

5) Bukti fisik (Tangibles) adalah penampilan dari sarana prasaran, karyawan dan fasilitas fisik lainnya;

Kualitas pelayanan yang diberikan kepada konsumennya berdasarkan ke lima dimensi, menunjukkan bahwa baik secara parsial ataupun simultan memiliki pengaruh yang positif terhadap kepuasan konsumen pada PT Sucofindo Batam (Lubis \& Andayani, 2017). Ternyata dari ke lima dimensi kualitas pelayanan memberikan pengaruh yang signifikan terhadap kepuasan konsumen adalah jaminan, setelah itu daya tanggap, empati, bukti fisik sedangkan penagruh terkecilnya dalah kehandalan, dimana 79,5\% kepuasan konsumen dipengaruhi oleh kualitas pelayanan, sedangkan sisanya ditentukan oleh variabel yang lainnya (Setiawan \& Setiawan, 2018). Kualitas pelayan memiliki pengaruh terhadap kepuasan dari konsumen, dimana dimensi yang dipergunakan untuk mengukur kualitas 


\section{Merita Bernik}

pelayanan menggunakan TERRA sedangkan kepuasan konsumen berdasarkan dimensi kesevaian dan harapan, berdasarkan penelitian yaang dilakukan oleh Sianipar (2018) memberikan hasil bahwa kualitas pelayanan memiliki pengaruh sebesar $75,3 \%$ terhadap kepuasan konsumen pada salah satu Mall di Pekan Baru. Berdasarkan penelitian yang dilakukan oleh Arianto (2018) selain kualitas pelayanan memiliki pengaruh terhadap kepuasan konsumen juga memiliki pengaruh terhadap loyalias konsumen.

\section{Kepuasan Konsumen}

Kepuasan konsumen tercipta ketika kenyataan lebih baik daripada harapan akan suatu produk atau jasa yang dirasakan oleh konsumennya (Kotler \& Keller, 2019). Kepuasan konsumen dapat diukur melalui 5 dimensi dari kualitas jasa yang diberikan oleh perusahaan. Berdasarkan 5 dimensi tersebut, ternyata variabel responsiveness yang paling dominan terhadap kepuasan pelanggan pada perusahaan yang bergerak di bidang tour dan travel (Imanuel \& Tanoto, 2019). Hal ini menunjukkan bahwa dimensi mana yang memilikiperanan yang penting dalam kepuasn konsumen, sangat tergantung kepada jenis perusahaannya, karena memang jasa memiliki sifat yang unik dan sulit untuk diukur dibandingkan produk, seperti kualitas jasa yang diberikan pada salah satu cafe di bandung menunjukkan bahwa dimensi reliability memiliki nilai tertinggi dibandingkan dimensi lainnya, dan perbandingan antara kenyataan dan harapan dari konsumen juga menunjukkan hasil bahwa kenyataan berada di bawah harpan sehingga adanya ketidakpuasan dari konsumen (Arindiaty \& Bernik, 2017).Kepuasan konsumen dapat ditentukan berdasarkan kualitas pelayanan, hasil yang diperoleh bahwa kualitas pelayanan memiliki pengaruh yang posistif baik secara parsial ataupun simultan terhadap kepuasan konsumen, terutama dalam dimensi empati (Krisdianti, Sunarti, 2019). Selain kualitas pelayanan yang perlu diperhatikan adalah kualitas produk, dimana ternyata kualitas produk juga memiliki pengaruh yang signifikan terhadap kepuasan konsumen (Lesmana \& Ratnasari, 2019). Dalam menentukan kepuasan konsumen dapat menggunakan lima variabel kualitas pelayanan yaitu pelayanan bersifat nyata, dapat dipercaya, bersikap tangguh, dapat menjamin dan menunjukkan kesungguhan, dari ke lima variabel tersebut diperolah hasil bahwa variabel kesungguhan merupakan variabel yang paling berpengaruh terhadap kepuasan konsuman,sedangkan baik secara parsial ataupun simultan ke lima variabel kualitas pelayanan memiliki pengaruh terhadap kepuasan konsumen (Affandi et al., 2017).

\section{METODE}

\section{Jenis Penelitian}

Metode penlitian yang dipergunakan adalah metoda deskriptif, dimana dalam metoda ini akan diberikan gambaran yang spesifik dari suatu kondisi ataupun situasi yang ingin kita ungkapkan kebenarannya. Hasil dari penelitian tersebut merupakan gambaran yang 
terperinci mengenai persoalan atau jawaban dari peranyaan yang diungkapkan dalam penelitian (Neuman \& Lawrence, 2017). Data yang dipergunakan merupakan data primer dan data sekunder. Data sekunder merupakan data yang diperoleh dari perusahaan berupa jumlah konsumen yang dimiliki Gold's Gym, informasi lainnya yang berkenaan dengan perkembangan dari Gold's Gym. Data primer diperoleh dengan melakukan observasi, wawancara dan penyebaran kuesioner.

\section{Data dan Sampel}

Teknik sampling yang dipergunakan dalam penyebaran kuesioner adalah Nonprobabbility Sampling, dimana yang menjadi responden adalah hanya konsumen yang pernah menggunakan fasilitas dari Gold's Gym. Jenis sampling yang dipergunakan adalah purposive sampling, responden adalah member dari Gold's Gym dan juga non member yang sering menggunakan fasilitas Gold's Gym (minimal dua kali menggunakan fasilitas tersebut). Wawancara dilakukan terhadap customer service, manajer dan juga trainer dari fitness center tersebut. Kuesioner yang disebarkan kepada 100 member dan pengguna fasilitas Golds Gym berdasarkan lima dimensi kualitas pelayanan, adapun operasional variabelnya dapat dilihat pada Tabel 2.

\section{Tehnik Pengolahan Data}

Data yang telah diperoleh berdasarkan obeservasi, wawancara dan penyebaran kuesioner, kemudian akan dilakukan pengolahan dengan tahapan sebagai berikut:

- Menentukan bobot untuk setiap jawaban responden

- Kuesioner yang disusun terbagi menjadi dua bagian, yaitu bagian kinerja atau tingkat pelayanan dan bagian harapan atau derajat kepentingan. Bobot untuk setiap jawaban terdiri dari 5 variabel jawaban. Berikut penetapan bobot untuk setap variabel jawaban :

Sangat Setuju atau Sangat Penting : 5

Setuju atau Penting $\quad: 4$

Cukup Setuju atau Cukup Penting : 3

Kurang Setuju atau Kurang Penting : 2

Tidak Setuju atau Tidak Penting : 1

Menentukan total skor kinerja dan harapan

Total skor = variabel jawaban $\mathrm{x}$ skor harapan

Mengubah skor dalam bentuk presentase. Data yang diolah kemudian dirubah menjadi data interval.

Nilai $(\%)=\underline{\text { nilai numulatif item } \times 100}$

nilai frekuensi 
Tabel 2.

Variabel indikator penelitian dimensi SERVQUAL

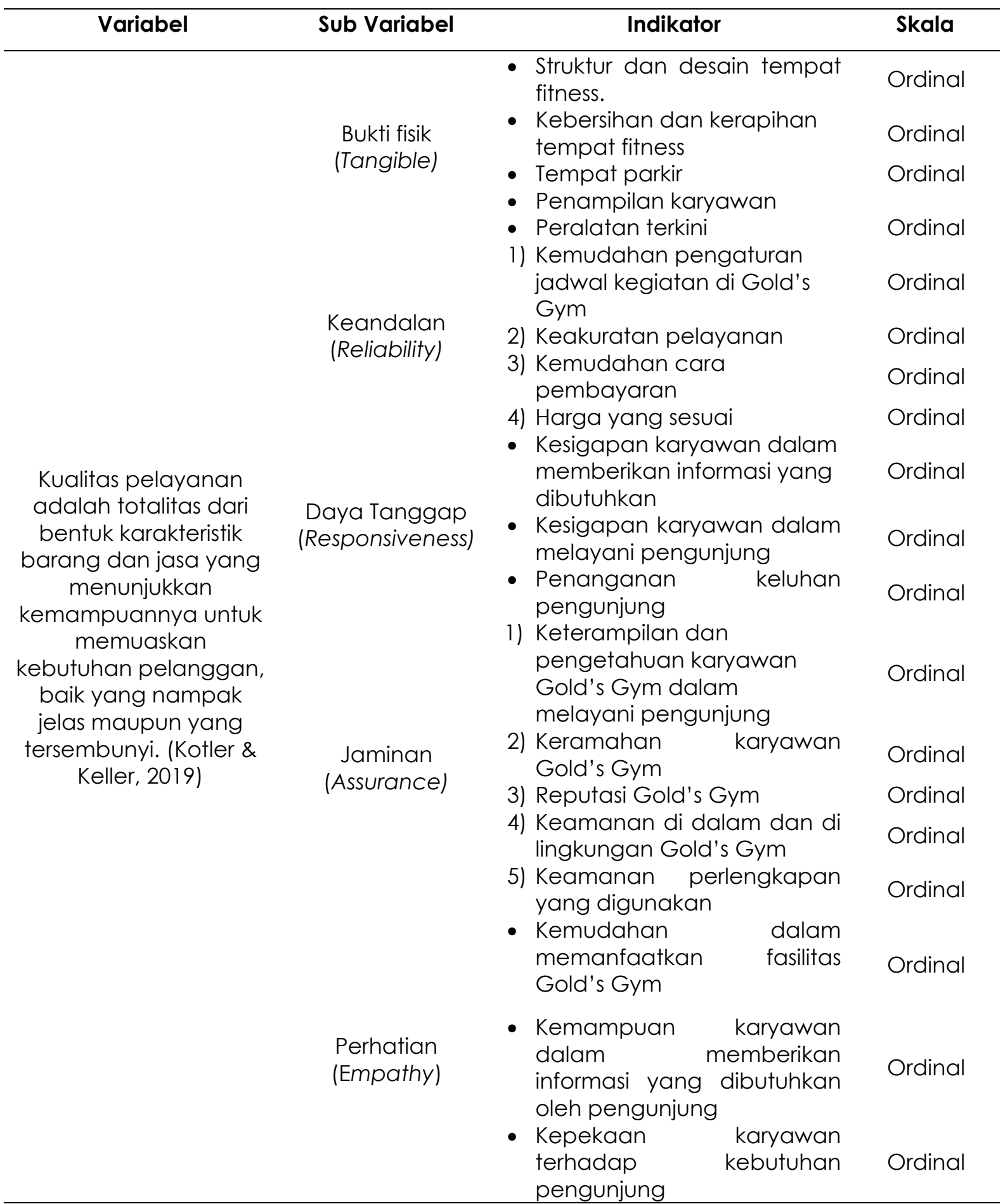

Setelah mengetahui skor rata-rata dan jawaban responden, kemudian hasil akan dimasukkan kedalam garis kontinum dengan kecendrungan jawaban responden berdasarkan pada nilai rata-rata skor yang selanjutnya dikategorikan pada rentang skor menggunakan rumus sebagai berikut:

$$
r=\frac{\mathrm{ST}-\mathrm{SR}}{K}
$$




$$
\mathrm{r}=\frac{5-1}{5}=0,8
$$

Keterangan:

$r \quad=$ Rentang / skala

ST $=$ Skor jawaban tertinggi

$S R=$ Skor jawaban terendah

$\mathrm{K}=$ Kategori

\begin{tabular}{|c|c|c|c|c|}
\hline Sangat Setuju & Tidak Setuju & Cukup Setuju & Setuju & Sangat Setuju \\
\hline Sangat Tidak Penting & Tidak Penting & Cukup Penting & Penting & Sangat Penting \\
\hline 1 & 8 & & & 5 \\
\hline
\end{tabular}

Gambar 1.

Garis Kontinum

Membuat interpretasi dari setiap data kuesioner yang telah diolah, menentukan rata-rata kinerja dan rata-rata harapan dan membuat diagram Kartesius yang bertujuan agar dapat mengetahui tingkat kinerja dan kepuasan pada kualitas jasa yang telah diberikan oleh perusahaan kepada pelanggan dan tingkat harapan pelanggan terhadap kinerja yang diberikan oleh perusahaan. Melalui diagram kartesius terdapat lima tahapan. Dari kelima tahapan tersebut maka kita dapat melihat indikator-indikator yang mayoritas menampati kuadran-kuadran yang terdapat pada diagram kartesius. Posisi setiap kuadran dapat digambarkan pada Gambar 2.

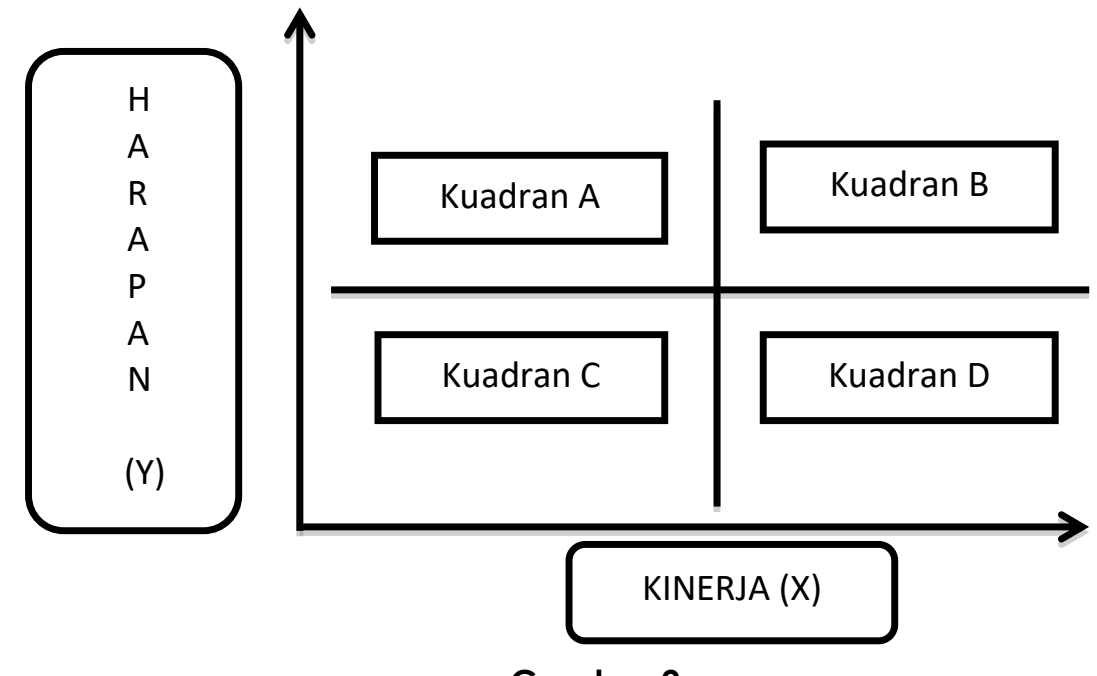

Gambar 2.

Diagram Kartesius

\section{Kuadran A (Prioritas Utama)}

Kinerja suatu variabel adalah lebih rendah dari keinginan pelanggan sehingga perusahaan harus meningkatkan kinerja agar optimal. 


\section{Merita Bernik}

\section{Kuadran B (Pertahankan Presentasi)}

Kinerja dan keinginan pelanggan pada suatu variabel berada pada tingkat tinggi dan sesuai, sehingga perusahaan cukup mempertimbangkan kinerja variabel tersebut.

\section{Kuadran C (Prioritas Rendah)}

Kinerja dan keinginan pelanggan pada suatu variabel berada pada tingkat rendah, sehingga perusahaan belum perlu melakukan perbaikan.

\section{Kuadran D (Berlebihan)}

Kinerja perusahaan berada dalam tingkat tinggi tetapi keinginan pelanggan akan kinerja dari variabel tersebut hanya rendah, sehingga perusahaan perlu mengurangi hasil yang dicapai agar dapat mengefisiensikan sumberdaya perusahaan.

\section{HASIL DAN DISKUSI}

\section{Pelaksanaan Kualitas Pelayanan Pada Gold's Gym}

Kualitas pelayanan ditentukan oleh kemampuan yang dimiliki oleh perusahaan dalam memenuhi kebutuhan dan keinginan pelanggan sesuai dengan ekspektasi pelanggan (Parasuraman, Berry, 1985). Pelaksanaan kualitas pelayanan di Gold's Gym Bandung dapat dilihat dari dimensi kualitas pelayanan yang terdiri dari tangible, empathy, responsiveness, reliability dan assurance.

\section{Tangible}

Tangible adalah bukti konkret dari kemampuan suatu perusahaan untuk menampilkan sisi terbaik kepada pelanggan. Terdiri dari struktur dan desain Gymnasium, kebersihan dan kerapihan Gymnasium, tempat parkir dan penampilan karyawan.

\section{Reliability (Kehandalan)}

Reliability merupakan kemampuan perusahaan untuk memberikan layanan yang dijanjikan secara akurat tanpa membuat kesalahan dan menyampaikan jasanya sesuai dengan waktu yang disepakati. Hal ini meliputi kemudahan pengaturan jadwal kegiatan di Gold's Gym, keakuratan pelayanan, kemudahan cara membayar serta harga yang sesuai dimana hal-hal tersebut dapat menjadi nilai tambah bagi Gold's Gym

\section{Responsiveness (Daya Tanggap)}

Responsiveness merupakan kesediaan dan kemampuan karyawan untuk membantu para pelanggan dan merespon permintaan mereka dengan tanggap serta memberikan pelayanan yang cepat saat menangani transaksi.Hal ini meliputi kesigapan karyawan 
dalam memberikan informasi yang dibutuhkan, kesigapan karyawan dalam melayani pengunjung serta penanganan keluhan pelanggan di Gold's Gym.

\section{Assurance (Jaminan)}

Assurance merupakan perilaku para karyawan sehingga mampu menumbuhkan kepercayaan pelanggan terhadap perusahaan serta mampu menciptakan rasa aman bagi para pelanggan. Hal ini meliputi keterampilan dan pengetahuan karyawan dalam melayani pengunjung, keramahan karyawan Gold's Gym, reputasi Gold's Gym serta keamanan di dalam dan di lingkungan Gold's Gym.

\section{Emphaty (Perhatian)}

Emphaty merupakan perhatian yang diberikan perusahaan secara personal kepada pelanggannya dengan berusaha memahami masalah yang dihadapi oleh pelanggan, mengerti kebutuhan pelanggan, dan bertindak demi kepentingan pelanggan. Hal tersebut meliputi kemudahan dalam memanfaatkan fasilitas Gold's Gym, kemampuan karyawan dalam memberikan informasi yang dibutuhkan oleh pengunjung serta kepekaan karyawan dalam memberikan informasi yang dibutuhkan oleh pengunjung juga perlu diperhatikan sebagai indikator pelayanan yang baik di Gold's Gym Bandung.

\section{Kualitas Pelayanan pada Gold's Gym Berdasarkan Tanggapan Konsumen}

Berdasarkan hasil penyebaran kuesioner kepada 100 responden yang telah mengunjungi Gold's Gym Braga, diperoleh data identitas responden yang meliputi jenis kelamin, usia, pendidikan/pekerjaan, melakukan fitness atau aerobik dan kunjungan ke Gold's Gym.

\section{Klasifikasi Karakteristik}

\section{Jenis Kelamin}

Wanita lebih mendominasi dalam berkunjung ke Gold's Gym Braga Bandung yaitu 68,0 \% atau sebanyak 68 responden, sedangkan pengunjung pria memiliki presentase sebesar $32,0 \%$ atau berjumlah 32 orang. Hal tersebut terjadi karena wanita cenderung lebih menyukai fitnessuntuk kebugaran dan kesehatan badan. 


\section{Merita Bernik}

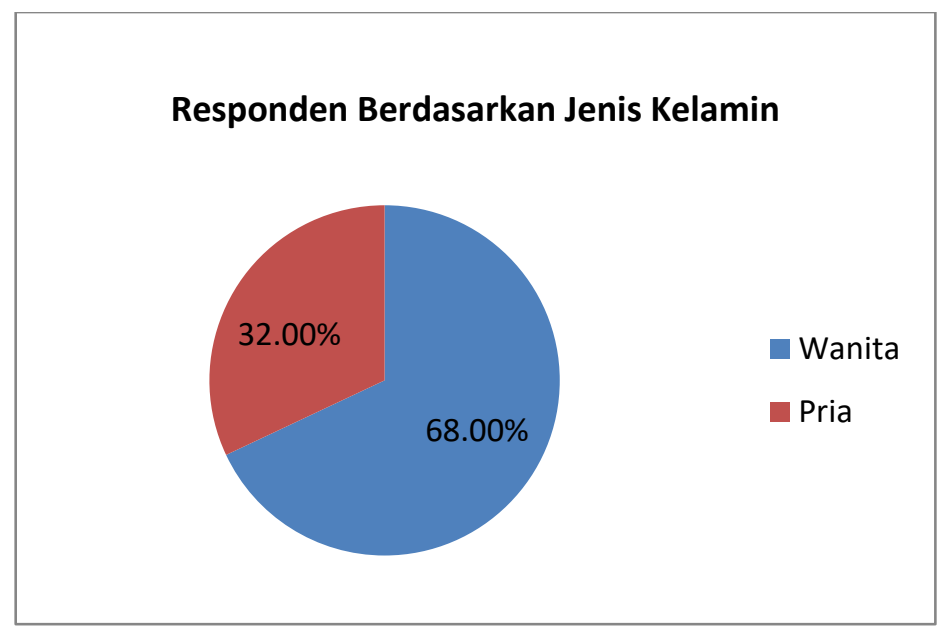

Gambar 3.

Diagram Berdasarkan Jenis Kalamin

\section{Usia}

Pegunjung Gold's Gym Bandung berasal dariusia 17 tahun, namun golongan usia terbanyak yang mengunjungi Gold's Gym Bandung berkisar pada usia 25 tahun sampai 30 tahun dengan presentase sebesar 49\%. Hal ini dikarenakan Gold's Gym Bandung berlokasi strategis. Gold's Gym Bandung juga merupakan tempat fitnesmodern yang memiliki program dan fasilitas lengkap. Menjadikan tempat fitness ini cocok menjadi pilihan masyarakat untuk pola hidup sehat.

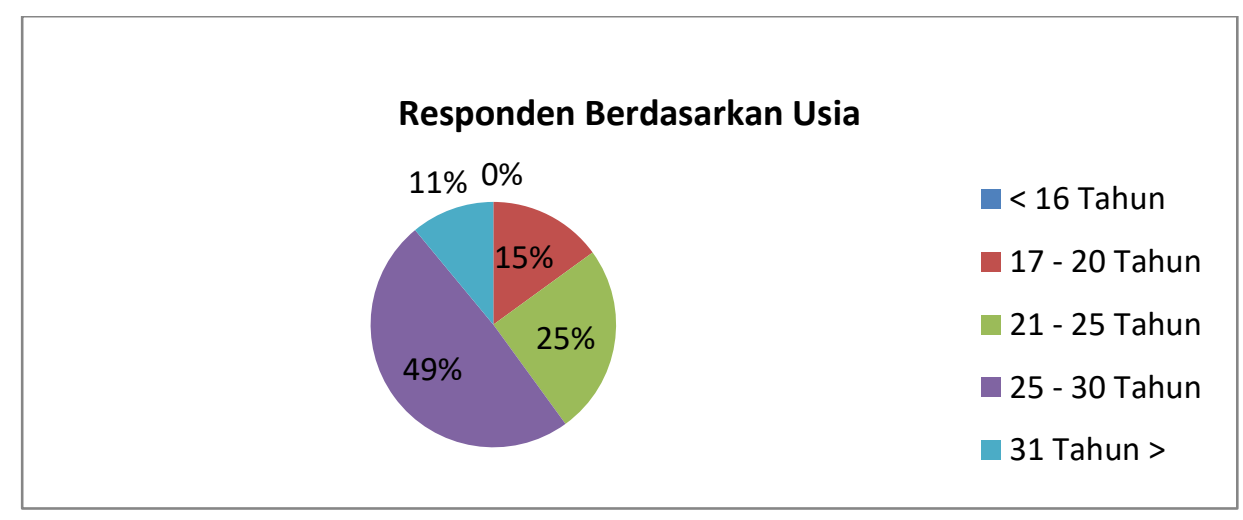

Gambar 4.

Diagram Usia Responden

\section{Pekerjaan}

Pengunjung Golds Gym Bandung berasal dari berbagai macam pekerjaan salah satunya karyawan yang paling banyak mengunjungi Golds Gym Bandung. Hal ini dikarenakan Gold's Gym Bandung berlokasi strategis. Gold's Gym Bandung juga merupakan tempat fitnessmodern dan memiliki program dan fasilitas lengkap. Menjadikan tempat fitness ini cocok menjadi pilihan masyarakat untuk pola hidup sehat. 


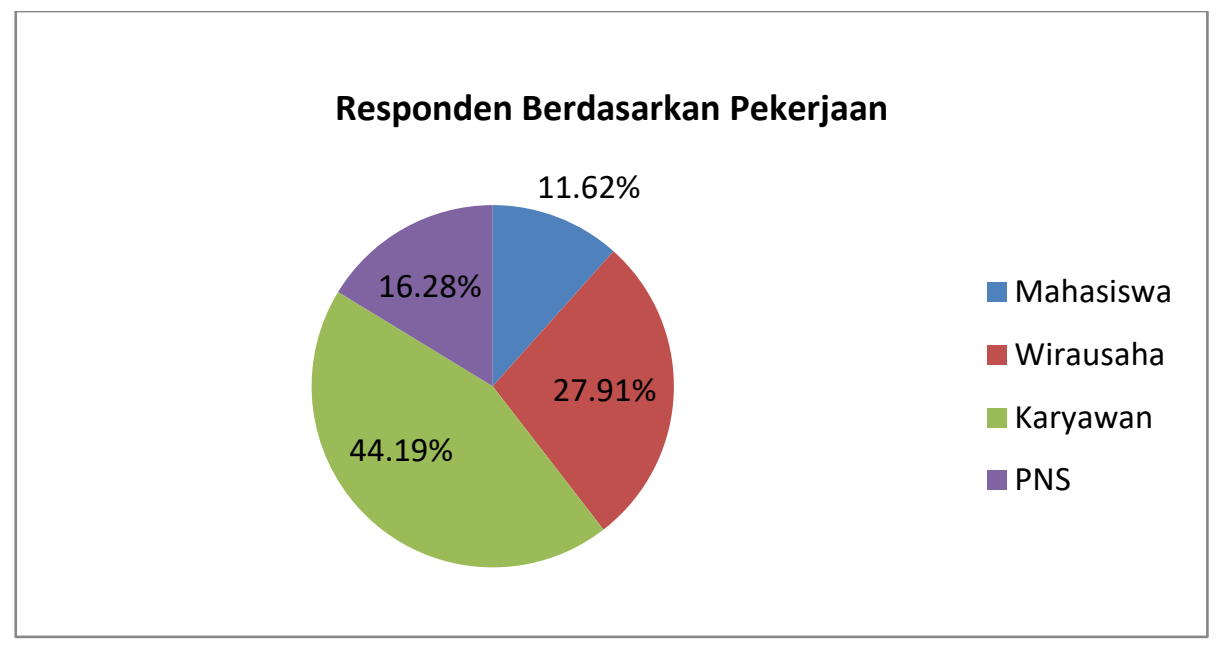

Gambar 5.

Diagram Pekerjaan Responden

\section{Kunjungan}

Kunjungan yang dilakukan ke Gold's Gym paling banyak dilakukan 1 bulan 1 kali dengan persentase sebesar $57 \%$.

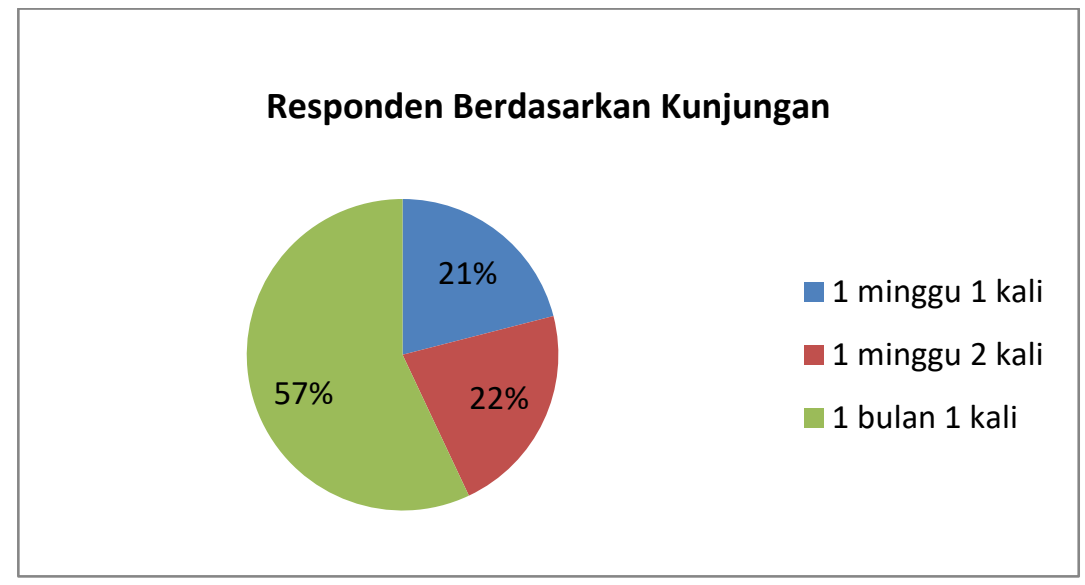

Gambar 6.

Diagram Kunjungan Konsumen

\section{Analisis Tanggapan Responden Terhadap Kualitas Pelayanan Gold's Gym Bandung}

Dalam melakukan penilaian terhadap kualitas pelayanan Gold's Gym Bandung, penulis menggunakan indikator penilaian skor dengan metode sebagai berikut:

\section{Tabel 3.}

Indikator penilaian skor

\begin{tabular}{ll}
\hline Rata- Rata Skor & Kuadran \\
\hline Harapan $>4,5$ dan Kenyataan $<3,7$ & A \\
Harapan $>4,5$ dan Kenyataan $>3,7$ & B \\
Harapan $<4,5$ dan Kenyataan $<3,7$ & C \\
Harapan $<4,5$ dan Kenyataan $>3,7$ & D \\
\hline
\end{tabular}




\section{Tanggapan Responden terhadap Tangible (Bukti Fisik)}

Berikut adalah penilaian konsumen terhadap bukti fisik yang dimiliki Gold's Gym Braga Bandung meliputi struktur dan desain tempat fitness, kebersihan dan kerapihan tempat fitness, tempat parkir dan penampilan karyawan

Tabel 4.

Tangible (Bukti Fisik)

\begin{tabular}{lccc}
\hline \multicolumn{1}{c}{ Indikator } & \multicolumn{2}{c}{ Rata-Rata Skor } & \multirow{2}{*}{ Kuadran } \\
\hline Struktur dan desain tempatfitness & 4,30 & Kenyataan & Kus \\
Kebersihan dan kerapihan tempat fitness & 4,60 & 4,00 & $\mathrm{~B}$ \\
Tempat parkir & 3,90 & 3,09 & $\mathrm{~B}$ \\
Penampilan karyawan & 3,86 & 3,31 & $\mathrm{C}$ \\
Peralatan Terkini & 4,60 & 4,00 & $\mathrm{C}$ \\
\hline
\end{tabular}

3,64

\begin{tabular}{|c|c|c|c|c|}
\hline Sangat Setuju & Tidak Setuju & Cukup Setuju & Setuju & Sangat Setuju \\
\hline Sangat Tidak Penting & Tidak Penting & Cukup Penting & Penting & Sangat Penting \\
\hline 1 & 1,8 & 2,6 & & 4,2 \\
\hline
\end{tabular}

\section{Gambar 7.}

Garis Kontinum Dimensi Tangible

Berdasarkan garis kontinum untuk Tabel 4 dapat dilihat bahwa total rata-rata skor harapan lebih tinggi dibandingkan dengan total rata-rata skor kinerja mengenai kualitas jasa/pelayanan dimensi tangible. Tanggapan responden terhadap kinerja Golds Gym pada dimensi tangible atau bukti fisik berada dalam kategori 'baik' dilihat berdasarkan total ratarata skor kinerja pada dimensi ini adalah sebesar 3,64.Sedangkan harapan responden terhadap kualitas jasa dimensi tangible atau bukti fisik ini berada pada kategori 'sangat penting' dengan total rata-rata skor harapan sebesar 4,25. Hal ini menunjukkan kepuasan yang dirasakan pelanggan masih lebih rendah dibandingkan dengan harapan pelanggan. GoldyGym masih perlu ditingkatkan dan diperhatikan kembali mengingat penilaian harapan responden yang menilai dimensi ini sangat penting.

\section{Tanggapan Responden terhadap Reliability (Kehandalan)}

Berikut adalah penilaian konsumen terhadap kehandalan yang dimiliki Gold's Gym Braga Bandung meliputi kemudahan pengaturan jadwal kegiatan, keakuratan pelayanan, kemudahan cara pembayaran serta harga yang sesuai.

Berdasarkan garis kontinum untuk Tabel 5 memperlihatkan bahwa total rata-rata skor kinerja sebesar 3,68 hal ini menunjukkan kualitas jasa terhadap kinerja dalam dimensi reliability 
berada dalam kategori 'baik' namun, masih lebih rendah dibandingkan dengan total ratarata skor harapan pelanggan sebesar 4,23 yang berada pada kategori 'sangat penting' dimana seorang pegawai mampu memberikan pelayanan sesuai yang dijanjikan dan membantu penyelesaian masalah yang dihadapi pelanggan dengan cepat.

Tabel 5.

Reliability (Kehandalan)

\begin{tabular}{lccc}
\hline \multicolumn{1}{c}{ Indikator } & \multicolumn{2}{c}{ Rata-Rata Skor } & \multirow{2}{*}{ Kuadran } \\
\hline Kemudahan pemesanan pelayanan & 4,33 & Kenyataan & Kuad \\
Keakuratan pelayanan & 4,30 & 3,75 & $\mathrm{~B}$ \\
Kemudahan cara pembayaran & 4,30 & 3,90 & $\mathrm{~B}$ \\
Harga yang sesuai & 4,02 & 3,60 & $\mathrm{~B}$ \\
\hline
\end{tabular}

\section{3,68}

\begin{tabular}{|c|c|c|c|c|}
\hline Sangat Setuju & Tidak Setuju & Cukup Setuju & Setuju & Sangat Setuju \\
\hline Sangat Tidak Penting & Tidak Penting & Cukup Penting & Penting & Sangat Penting \\
\hline 1 & 1,8 & 2,6 & & 4,2 \\
\hline
\end{tabular}

Gambar 8.

Garis Kontinum Dimensi Reliability

\section{Tanggapan Responden terhadap Responsiveness (Daya Tanggap)}

Berikut adalah penilaian konsumen terhadap daya tanggap yang dimiliki Golds Gym Braga Bandung terhadap Kesigapan karyawan dalam memberikan informasi yang dibutuhkan, kesigapan karyawan dalam melayani dan penanganan keluhan.

\section{Tabel 6.}

Responsiveness (Daya Tanggap)

\begin{tabular}{|c|c|c|c|}
\hline \multirow{2}{*}{ Indikator } & \multicolumn{2}{|c|}{ Rata-Rata Skor } & \multirow{2}{*}{ Kuadran } \\
\hline & Harapan & Kenyataan & \\
\hline $\begin{array}{l}\text { Kesigapan karyawan dalam memberikan } \\
\text { informasi yang dibutuhkan }\end{array}$ & 4,25 & 4,05 & A \\
\hline $\begin{array}{l}\text { Kesigapan karyawan dalam melayani } \\
\text { pengunjung }\end{array}$ & 4,27 & 4,00 & A \\
\hline Penanganan keluhan & 4,16 & 4,10 & C \\
\hline
\end{tabular}

\begin{tabular}{l|c|c|c|cc}
\multicolumn{2}{c}{ Sangat Setuju } & Tidak Setuju & Cukup Setuju & \multicolumn{2}{c}{$\mathbf{4 , 0 5} \bigcirc$} \\
\hline Sangat Tidak Petuju & Sangat Setuju \\
1 & Tidak Penting & Cukup Penting & Penting & Sangat Penting \\
1,8 & 2,6 & 3,4 & & 4,2 & 5
\end{tabular}

Gambar 10.

Garis Kontinum Dimensi Responsiveness 


\section{Merita Bernik}

Berdasarkan garis kontinum untuk Tabel 6 mengenai kualitas jasa/ pelayanan dimensi Responsiveness, memperlihatkan bahwa total rata-rata skor kinerja sebesar 4,05 berada dalam kategori 'baik' namun, masih lebih rendah dibandingkan dengan total rata-rata skor harapan pelanggan sebesar 4,22 yang menilai bahwa kualitas jasa pada harapan dalam dimensi responsiveness itu sangat penting. Oleh karena itu, pada dimensi responsiveness ini diharapkan Gold's Gym dapat memperbaiki dan meningkatkan kembali kualitas pelayanan yang diberikan oleh pegawainya agar kepuasan pelanggan tercapai sesuai dengan harapan pelanggan.

\section{Tanggapan Responden terhadap Assurance (Jaminan)}

Berikut adalah penilaian konsumen terhadap jaminan yang dimiliki Gold's Gym Braga Bandung meliputi keterampilan dan pengetahuan karyawan Gold's Gym dalam melayani pengunjung, keramahan karyawan Gold's Gym, reputasi Gold's Gym serta keamanan di dalam dan lingkungan restoran.

Tabel 7.

Assurance (Jaminan)

\begin{tabular}{|c|c|c|c|}
\hline \multirow{2}{*}{ Indikator } & \multicolumn{2}{|c|}{ Rata-Rata Skor } & \multirow{2}{*}{ Kuadran } \\
\hline & Harapan & Kenyataan & \\
\hline Keterampilandan pengetahuan karyawan Gold's & 4,46 & 4,05 & B \\
\hline Gym dalam melayani pengunjung & & & \\
\hline Keramahan karyawan Gold's Gym & 4,30 & 4,30 & B \\
\hline Reputasi Gold's Gym & 4,39 & 3,48 & B \\
\hline Keamanan di dalam dan di lingkungan Gold's Gym & 4,23 & 4,00 & A \\
\hline Keamanan perlengkapan yang digunakan & 4,46 & 4,30 & B \\
\hline
\end{tabular}

\begin{tabular}{|c|c|c|c|c|}
\hline Sangat Setuju & Tidak Setuju & Cukup Setuju & Setuju & Sangat Setuju \\
\hline Sangat Tidak Penting & Tidak Penting & Cukup Penting & Penting & Sangat Penting \\
\hline 1 & 1,8 & 2,6 & & 4,2 \\
\hline
\end{tabular}

\section{Gambar 11.}

Garis Kontinum Dimensi Assurance

Berdasarkan garis kontinum untuk Tabel 4.9 mengenai kualitas jasa/ pelayanan dimensi Assurance, menunjukkan bahwa total rata-rata skor kinerja sebesar 4,02 hal ini menunjukkan bahwa kualitas jasa pada kinerja dalam dimensi assurance berada dalam kategori 'baik', tetapi memang masih dikatakan lebih rendah dibandingkan dengan total rata-rata skor harapan pelanggan yaitu sebesar 4,36 yang artinya responden menilai bahwa kualitas jasa pada harapan dalam dimensi assurance ini 'sangat penting'. Oleh karena itu, Gold's Gymharus lebih memperhatikan pelanggannya terutama dalam segi jaminan yang akan diberikan kepada pelanggannya. 


\section{Tanggapan Responden terhadap Emphaty (Perhatian)}

Berikut adalah penilaian konsumen terhadap perhatian yang dimiliki Gold's Gym Braga Bandung meliputi kemudahan dalam memanfaatkan fasilitas restoran, kemampuan karyawan dalam memberikan informasi yang dibutuhkan oleh pengunjung serta kepekaan karyawan terhadap kebutuhan pengunjung.

\section{Tabel 8.}

Empathy (Perhatian)

\begin{tabular}{lccc}
\hline \multicolumn{1}{c}{ Indikator } & \multicolumn{2}{c}{ Rata-Rata Skor } & \multirow{2}{*}{ Kuadran } \\
\hline Kemudahan dalam memanfaatkan fasilitas Gold's Gym & 4,30 & 4,10 & B \\
Kemampuan karyawan dalam memberikan informasi & 4,00 & 4,05 & $\mathrm{C}$ \\
yang dibutuhkan oleh pengunjung & 4,30 & 4,30 & $\mathrm{C}$ \\
\hline
\end{tabular}

\begin{tabular}{|c|c|c|c|c|}
\hline \multirow[b]{2}{*}{ Sangat Setuju } & \multirow[b]{2}{*}{ Tidak Setuju } & \multirow[b]{2}{*}{ Cukup Setuju } & \multicolumn{2}{|c|}{$4,15 \bigcirc$} \\
\hline & & & Setuju & Sangat Setuju \\
\hline Sangat Tidak Penting & Tidak Penting & Cukup Penting & Penting & Sangat Penting \\
\hline 1 & 8 & 6 & & 4,2 \\
\hline
\end{tabular}

\section{Gambar 12.}

Garis Kontinum Dimensi Empathy

Berdasarkan garis kontinum untuk Tabel 8 mengenai kualitas jasa/ pelayanan dimensi Empathy, menunjukkan bahwa total rata-rata skor kinerja sebesar 4,15 hal ini menunjukkan bahwa kualitas jasa pada kinerja dalam dimensi Empathyberada dalam kategori 'baik', tetapi memang masih dikatakan lebih rendah dibandingkan dengan total rata-rata skor harapan pelanggan yaitu sebesar 4,2 yang artinya responden menilai bahwa kualitas jasa pada harapan dalam dimensi Empathyini 'sangat penting'. Oleh karena itu, Gold's Gymharus lebih memperhatikan pelanggannya terutama dalam segi Perhatian yang akan diberikan kepada pelanggannya.

Berdasarkan tabel 9 dapat diketahui bahwa nilai total skor kepuasan konsumen (Kenyataan) di Gold's Gym masih di bawah nilai skor harapan, namun demikian masih masuk dalam nilai baik dan memuaskan, hanya saja perlu peningkatan dalam berbagai aspek. Aspek yang perlu ditingkatkan dan diperhatikan adalah nilai skor dengan skor 3,64 dan 3,68 dimana aspek tersebut adalah, struktur dan desain fitnes, lahan parkir, penampilan karyawan, layanan pemesanan, keakuratan layanan, kemudahan cara pembayaran dan harga. 
Tabel 9.

Rekapitulasi Kepuasan Konsumen

\begin{tabular}{clcc}
\hline No. & \multicolumn{1}{c}{ Pertanyaan } & Harapan & Kenyataan \\
\hline 1 & Struktur dan desain tempat fitness & 4,30 & 3,80 \\
2 & Kebersihan dan kerapihan tempat fitness & 4,60 & 4,00 \\
3 & Tempat parkir & 3,90 & 3,09 \\
4 & Penampilan karyawan & 3,86 & 3,31 \\
5 & Peralatan terkini & 4,60 & 4,00 \\
& Rata-rata Skor & $\mathbf{4 , 2 5}$ & $\mathbf{3 , 6 4}$ \\
6 & Kemudahan pemesanan pelayanan & 4,33 & 3,75 \\
7 & Keakuratan pelayanan & 4,30 & 3,50 \\
8 & Kemudahan cara pembayaran & 4,30 & 3,90 \\
9 & Harga yang sesuai & 4,02 & 3,60 \\
& Rata-rata Skor & $\mathbf{4 , 2 3}$ & $\mathbf{3 , 6 8}$ \\
10 & Kesigapan karyawan dalam memberikan informasi yang & 4,05 & 4,05 \\
& dibutuhkan & 4,27 & 4,00 \\
11 & Kesigapan karyawan dalam melayani pengunjung & 4,16 & 4,10 \\
12 & Penanganan keluhan & $\mathbf{4 , 2 2}$ & $\mathbf{4 , 0 5}$ \\
& Rata-rata Skor & 4,46 & 4,05 \\
13 & Keterampilan dan pengetahuan karyawan Gold's Gym & 4,30 & 4,30 \\
14 & dalam melayani pengunjung & 4,39 & 4,48 \\
15 & Keramahan karyawan Gold's Gym & 4,23 & 4,00 \\
16 & Keputasi Gold's Gym & 4,46 & 4,30 \\
17 & Keamanan di dalam dan di lingkungan Gold's Gym & $\mathbf{4 , 3 6}$ & $\mathbf{4 , 0 2}$ \\
18 & Rata-rata Skor & 4,30 & 4,10 \\
19 & Kemudahan dalam memanfaatkan fasilitas Gold's Gym & 4,30 & 4,05 \\
20 & Kemampuan karyawan dalam memberikan informasi & 4,00 & 4,30 \\
& yang dibutuhkan oleh pengunjung & 4,30 & \\
\hline & Rata-rata Skor & $\mathbf{4 , 2}$ &
\end{tabular}

\section{Analisa Diagram Kartesius}

Berdasarkan hasil diagram kartesius di pada gambar 13 dapat diketehui beberapa hal sebagai berikut:

\section{Kuadran A.}

Faktor-faktor yang terletak dalam kuadran ini dianggap sebagai faktor yang penting atau diharapkan oleh konsumen tetapi kinerja aktual yang ada pada saat ini belum memuaskan sehingga pihak manajemen berkewajiban mengalokasikan sumber daya yang memadai untuk meningkatkan kinerja berbagai faktor tersebut. Faktor-faktor yang terletak pada kuadran ini merupakan prioritas untuk ditingkatkan. Atribut - atribut yang masuk kedalam kuadran ini yaitu :

(9) Kesigapan karyawan dalam memberikan informasi yang dibutuhkan

(10) Kesigapan karyawan dalam melayani

(15) Keamanan di dalam dan lingkungan restoran 


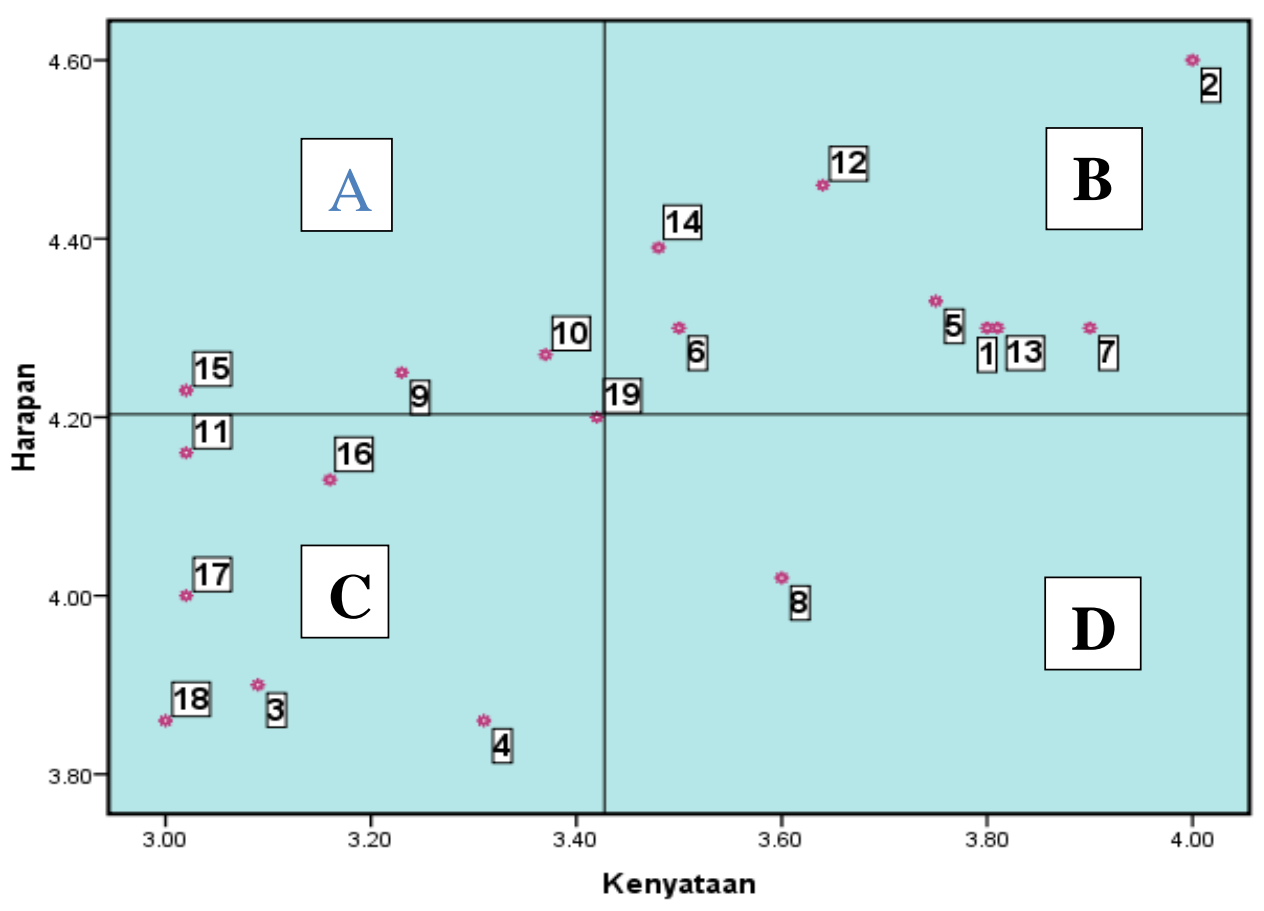

Gambar 13.

Hasil Diagram Kartesius

\section{Kuadran B.}

Faktor-faktor yang terletak pada kuadran ini dianggap penting dan diharapkan sebagai faktor penunjang bagi kepuasan konsumen sehingga pihak manajemen berkewajiban memastikan bahwa kinerja institusi yang dikelolanya dapat terus mempertahankan prestasi yang telah dicapai. Atribut - atribut yang masuk kedalam kuadran ini yaitu:

(1) Struktur dan desain tempat fitness

(2) Kebersihan dan kerapihan tempat fitness

(5) Kemudahan pengaturan jadwal kegiatan di Gold's Gym

(6) Keakuratan pelayanan

(7) Kemudahan cara pembayaran

(12) Keterampilan dan pengetahuan karyawan Gold's Gym dalam melayani

(13) Keramahan karyawan Gold's Gym

(14)Reputasi Gold's Gym

\section{Kuadran C.}

Faktor-faktor yang terletak pada kuadran ini mempunyai tingkat kinerja aktual yang rendah sekaligus dianggap tidak terlalu penting bagi konsumen sehingga manajemen tidak perlu memprioritaskan atau terlalu memberikan perhatian pada faktor-faktor tersebut. Atribut atribut yang masuk kedalam kuadran ini yaitu:

(3) Tempat parkir

(4) Penampilan karyawan

(11) Penanganan keluhan 


\section{Merita Bernik}

(16) Kemudahan dalam memanfaatkan fasilitas yang ada di Gold's Gym

(17) Kemampuan karyawan dalam memberikan informasi yang dibutuhkan oleh pengunjung

(18) Kepekaan karyawan terhadap kebutuhan pengunjung

\section{Kuadran D.}

Faktor-faktor yang terletak pada kuadran ini dianggap tidak terlalu penting atau tidak terlalu diharapkan sehingga pihak manajemen perlu mengalokasikan sumber daya yang terkait dengan faktor-faktor tersebut kepada faktor-faktor lain yang mempunyai prioritas penanganan lebih tinggi yang masih membutuhkan peningkatan. Atribut - atribut yang masuk kedalam kuadran ini yaitu:

(8) Harga yang sesuai

\section{SIMPULAN}

Kualitas pelayanan yang diberikan oleh Gold's Gym Bandung termasuk kedalam kategori baik, dimana konsumen baik member baru ataupun member aktif mendapatkan karamahan dari wellness coach serta informasi dari fasilitas yang akan diberikan. Selain itu semua program yang ditawarkan mampu memenuhi kebutuhan konsumen seperti turunnya berat badan sesuai dengan yang ditargetkan. Semua dimensi dari kualitas pelayanan telah dilaksanakan dengan baik oleh Gold's Gym.

Rata-rata nilai dari kelima variabel kualitas pelayanan untuk harapan sebesar 4,2 sedangkan untuk kenyataan sebesar 4,15. Hal tersebut menunjukan bahwa kenyataan masih belum sesuai dengan harapan konsumennya, walaupun dengan selisih yang kecil, tapi tetap saja hal tersebut harus menjadi perhatian dari Gold's Gym. Berdasarkan diagram kartesius yang termasuk ke dalam kuadran B merupakan faktor terpenting untuk memuaskan konsumen adalah struktur dan desain tempat fitness, kebersihan dan kerapihan tempat fitness, kemudahan pengaturan jadwal, keakuratan pelayanan, kemudahan cara pembayaran, keterampilan dan pengetahuan karyawan, keramahan karyawan dan reputasi Gold's Gym. Faktor-faktor tersebut harus secara berkesinambungan ditingkatkan agar kepuasan konsumen dapat tercapai.

\section{DAFTAR PUSTAKA}

Affandi, H., Muhammad, Z., dan Azmeri. 2017. Pengaruh Kualitas Pelayanan Terhadap Kepuasan Pelanggan pada Perusahaan Daerah Air Minum (PDAM) Tirta Mon Pase Kabupaten Aceh Utara. Jurnal Tehnik Sipil Universitas Syiah Kuala. 6(3): 297-308. 
Arianto, N. 2018. Pengaruh Kualitas Pelayanan terhadap Kepuasan Konsumen dan Loyalitas Pengunjung dalam Menggunakan Jasa Hotel Rizen Kedaton Bogor. Jurnal Pemasaran Kompetitif 1 (2): 83-101.

Arindiaty, A., dan Berni,k M. 2017. Analisis Kualitas Jasa dalam Meningkatkan Kepuasan Konsumen di Baker Street Cafe Bandung. Jurnal Bisnis Terapan, Vol 1, No. 1, 43-51

Imanuel, B. H., Tanoto, S. 2019. Pengaruh Kualitas Layanan Terhadap Kepuasan Pelanggan di PT Hastoco Tour and Travel. Jurnal AGORA. (7) 1.

Kotler, P., Keller, K. L. 2019. Markering Management. Ediisi 15, Boston: Pearson.

Kotler, P., dan Amstrong, G, M. 2017. Principles of Marketing. United Kingdom: Pearson.

Krisdianti, D. L., dan Sunarti. 2019. Pengaruh Kualitas Pelayanan terhadap Kepuasan Konsumen pada Restoran Pizza Hut Malang Town Square. Jurnal Administrasi Bisnis, 70(1): 36-44.

Kusuma, Y. 2017. Kesehatan Merupakan Kebutuhan Pokok Manusia Oleh Karena Itu Kesehatan adalah Hak Azasi Manuasi. Diperoleh 19 Mei 2019. https://www.scribd.com/document/361408763/Kesehatan-Merupakan-KebutuhanPokok-Manusia-Oleh-Karena-Itu-Kesehatan-Adalah-Hak-Azasi-Manusia.

Lubis, A. S., Andayani, N, R. 2017. Pengaruh Kualitas Pelayanan (Service Quality) Terhadap Kepuasan Pelanggan PT. Sucofindo Batam. Journal of Business Administation. 1(2): 232-243.

Lupiyadi, R. 2014 . Manajemen Pemasaran Jasa. Jakarta: Salemba Empa.

Neuman, W., dan Lawrence. 2017. Metodologi Penelitian Sosial: Pendekatan Kualitatif dan Kuantitatif. Edisi 7. Pearson.

Parasuraman, A., Zeithaml, A., Berry, L. L. Servqual: A Multiple-ltem Scale For Measuring Consumer Perc. Journal of Retailing; Greenwich 64(1). (Spring 1988): 12.

Tjiptono, Fandy. 2018. Service Management: Mewujudkan Layanan Prima.Edisi 3.

Lesmana dan Ratnasari, Rosa. 2019. Pengaruh Kualitas Produk dan Kualitas Palayanan terhadap Kepuasan Konsumen. Jurnal Pemasaran Kompetitif. 2(2): 115-129.

Setiawan, D., dan Setiawan, R, I. 2018. Analisis Kualitas Pelayanan terhadap Kepuasan Servis (Studi Kasus AHASS Kenari Motor). Jurnal Penelitian Manajemen Terapan (Penataran). 3(1): 93-107

Sianipar, R. U. S. 2018. Pengaruh Kualitas Pelayanan Customer Relation Terhadap Kepuasan Pengunjung di Mal SKA Pekanbaru. JOM Fisip. 5(1). 